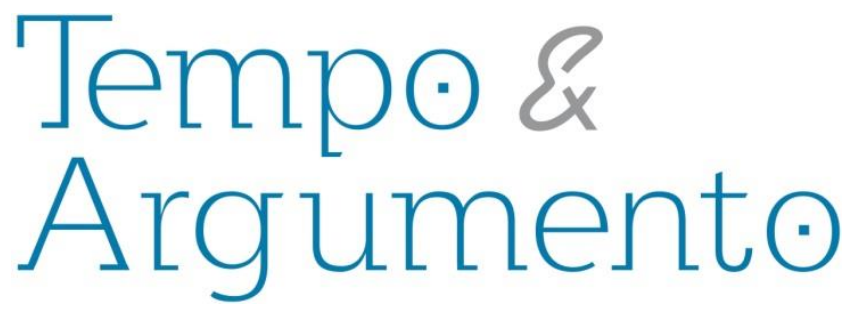

\title{
Desafios da produção historiográfica, subjetividades e ativismo político - Entrevista com James N. Green
}

\begin{abstract}
Entrevistado
O historiador estadunidense James N. Green é atualmente professor do Departamento de História da Brown University, onde ministra a disciplina de História da América Latina. Nessa mesma instituição dirige o Brown's Brazil Initiative, um centro de estudos sobre o Brasil que reúne pesquisadores estadunidenses e estrangeiros. $O$ historiador residiu no Brasil entre os anos de 1976 e 1982, período no qual viajou para diferentes partes do país e militou em grupos de esquerda. Essa experiência o motivou a pesquisar sobre a ditadura militar brasileira. Desses estudos surgiram importantes obras, tais como: "Além do Carnaval: a homossexualidade masculina no Brasil do século XX" (1999), "Apesar de Vocês: a oposição e a ditadura militar brasileira nos EUA" (2005). O referido historiador esteve no Brasil no mês de agosto para lançar seu mais recente livro relacionado a essa temática, "Revolucionário e Gay A Extraordinária Vida de Hebert Daniel", uma obra sobre o militante de esquerda Hebert Daniel e sua trajetória de vida.
\end{abstract}

Entrevista concedida em 29 de agosto de 2018, no Laboratório de Estudos de Gênero e História da Univerdidade Federal de Santa Catarina (UFSC).

\section{Entrevistadora}

Larissa Viegas de Mello Freitas

Doutoranda em História Universidade do

Estado de Santa Catarina.

Florianópolis - SC - Brasil

laryfreitas@hotmail.com

\section{Para citar esta entrevista:}

GREEN, James N. Desafios da produção historiográfica, subjetividades e ativismo político Entrevista com James N. Green. [Entrevista realizada em 29 de agosto de 2018]. Revista Tempo e Argumento, Florianópolis, v. 10, n. 25, p. 489 - 496, jul./jset. 2018. Entrevistadora: Larissa Viegas de Mello Freitas.

\section{DOI: $10.5965 / 2175180310252018489$}

http://dx.doi.org/10.5965/2175180310252018489 
Tempo e Argumento: Descreva a sua trajetória acadêmica e a sua inserção na historiografia brasileira a partir do tema da ditadura.

James Green: Isto tem a ver com o meu segundo livro, intitulado Apesar de Vocês, que considero uma publicação importante, pois via que aqui no Brasil a maior parte dos acadêmicos que pesquisavam a ditadura, e também as pessoas em geral da área da história, sustentavam um estereótipo simplista dos Estados Unidos, não percebendo que havia uma resistência à ditadura militar naquele país. Este movimento, apesar de pequeno e desconhecido, era importante, e a meu ver exerceu uma grande influência. Meu objetivo com este trabalho, portanto, foi desconstruir uma imagem errônea dos Estados Unidos. Entre os seus objetivos específicos estava explicar que houve uma resistência contra a ditadura militar vinda de fora. O segundo, que consiste no projeto Opening the Archives (Abrindo os Arquivos), pretende ajudar os pesquisadores brasileiros a ter acesso à documentação fundamental sobre a ditadura, especialmente aquela sobre a influência norte-americana aqui no Brasil ao longo dos anos da ditadura. Há também o novo trabalho de Herbert Daniel, que busca convidar as pessoas a repensar como contamos essas histórias sobre a ditadura, a partir de outros ângulos, de outras maneiras, com outros personagens e atores. Isto porque, durante muito tempo, as pesquisas se concentravam na luta armada e nesses setores da resistência, enfatizando o seu heroísmo e objetivando a sua celebração. Quanto a mim, eu queria realmente abordar essa temática de outro ângulo.

Tempo e Argumento: Como você percebe a relação, na sua atuação profissional, entre a produção das narrativas históricas e o ativismo no campo LGBT?

James Green: Eu tenho muita sorte de ter um companheiro que é um historiador muito sério, e que sempre me guiou. E sou muito rigoroso no meu trabalho acadêmico, pois fui muito bem treinado, e busco sempre a qualidade, para ganhar prêmios. Inclusive, várias das minhas obras e vários dos meus trabalhos ganharam prêmios respeitados por sua qualidade. Portanto, entendo que a minha subjetividade de 
uma pessoa gay que está pesquisando questões gays me leva a insights ou percepções e noções que outras pessoas talvez não tenham, por não conhecerem como eu este tema. Eu entendo a esquerda brasileira, e poderia escrever sobre a ditadura. Embora não tenha participado da luta armada, tenho um conhecimento da lógica interna da esquerda. Então isso me ajuda, essas subjetividades me aproximam do meu objeto de estudos. E também sou consciente das minhas subjetividades, e na medida do possível tentei trabalhá-las para que elas aumentassem a riqueza do trabalho e não diminuíssem o seu impacto. E é evidente que minhas subjetividades, minhas políticas estão embutidas no trabalho, constituindo apenas mais uma leitura, entre outras, do passado dessas pessoas. A minha leitura do movimento LGBT é uma leitura de quem era protagonista, e eu assumo esta subjetividade: sei que tenho uma visão parcial. Os antropólogos passam o tempo todo explicando a sua subjetividade, já eu, como branco, norteamericano, cis, de 67 anos, alto, etc., acho isso um pouco desnecessário. Está embutido no meu trabalho que eu tenho uma subjetividade, uma maneira de ler essa questão, que será parcial, como todos os trabalhos são parciais. Não existe objetividade.

Tempo e Argumento: Você considera que existe ativismo de sua parte nos campos da história pública, da história oral e da história das relações de gênero? Qual a importância disso?

James Green: O meu ativismo consiste em produzir materiais que não foram produzidos antes. Nesse sentido, tem duas grandes obras: o meu livro, Além do Carnaval, e Um Devasso no Paraíso de João Silério Trevisan. Tenho divergências políticas com ele, e o trabalho dele não é de historiador, e por isso tem outra qualidade, tem outros dotes que o meu trabalho não tem. Eu acredito em notas de pé de página, adoro fontes, gosto de documentos, de usar e de ler documentos, e de criticá-los. E todo o meu trabalho é político, no sentido de que eu estou oferecendo ao público novos olhares que não existem, novas maneiras de entender o passado, novos olhares 
para as pessoas que precisam entender o passado para viver bem com o presente. Portanto, a maior alegria que eu tive nessa turnê que estou fazendo no Brasil foi na semana passada. Um jovem ator de São Paulo me disse: "Eu nasci no Acre e descobri que era homossexual. Seu livro salvou a minha vida, porque eu li Além do Carnaval e percebi que poderia ter uma vida tranquila." E outra pessoa que leu outro trabalho que eu fiz e disse o seguinte sobre ele: "Nossa, aquilo que você escreveu foi tão importante para mim". Isso é a coisa mais linda que pode acontecer. É isso, e fazer um trabalho sério e rigoroso, mas que tenha uma função na sociedade. Eu não tenho nada contra as pessoas que queiram pesquisar coisas que não têm uma utilidade social e política óbvia, eu as respeito. Isso é totalmente legítimo, e não as estou marginalizando ou dizendo que o meu trabalho é melhor do que o de ninguém, mas essa foi a minha opção ao voltar para a academia: era conscientemente uma intervenção política. E para finalizar, uma outra parte dessa questão, sendo acadêmico, era a solidariedade com a realidade brasileira, que é complicada. Era um dever nos pronunciarmos contra o golpe, era fundamental, se acreditamos em uma democracia no Brasil, apoiar o Lula como candidato legítimo a presidente. Se eu lutei contra a ditadura e pela democracia, quero fortalecer essa democracia, mesmo sendo estrangeiro e não tendo cidadania brasileira, sem direito de votar aqui, mas respeitando a realidade brasileira.

Tempo e Argumento: E com relação à história do tempo presente, qual é a sua visão?

James Green: Há problemas com qualquer coisa que você pesquise. Se é algo mais atual, pode ser que a análise fique limitada pela falta de distância entre você e o material que você está pesquisando. Mas eu acho que é totalmente válido, eu não vejo problema na medida em que a pessoa é séria e honesta com a sua tentativa de analisar essa realidade, essa documentação, a realidade em volta. 
Tempo e Argumento: Por muito tempo se fez certa hierarquia da documentação escrita em relação à fonte oral, você acha que isso tem mudado? Como tem sido sua experiência com relação a isso?

James Green: Eu já fiz mais de trezentas entrevistas de história oral. Isso é fundamental, porque aqui no Brasil, especialmente em certos setores não há registros escritos, pois as pessoas não os guardam em suas casas, mas apenas na memória. As famílias queimam os documentos de parentes que são gays ou lésbicas. Portanto, obter essas lembranças do passado é fundamental. E também é parcial, como qualquer documento é parcial. A história oral também tem essa limitação de um passado parcial, filtrado com subjetividades, mas é uma fonte importante. E para quem não tem nenhum acesso a esse passado, a história oral é fundamental para dar pistas para você verificar com outras fontes, com outras atividades. Isso foi muito importante no trabalho sobre Herbert Daniel, pois ele deixou pistas, deixou uma versão da sua vida, mas eu precisava confirmar essas informações com outras fontes para também preencher as lacunas que existiam no trabalho dele e enriquecer aquela versão do seu passado.

Tempo e Argumento: Fale sobre seu novo livro, recém-lançado. Como foi o processo de concepção do tema, da pesquisa e da escrita?

James Green: Eu acho que quando consegui o relato da Dona Geni, a mãe do Daniel, percebi que tinha que fazer algo. Eu nunca tinha feito uma biografia, não sabia como fazer, mas quis tentar fazer. Assim como antes do meu primeiro livro, Além do Carnaval, eu nunca tinha feito história social, não sabia como fazer, então eu tentei. E foi um desafio também para não repetir a mesma temática. Pensei que, se fosse trabalhar com homossexualidade de novo, queria fazer de um modo diferente. Então este foi um grande desafio, fazer uma biografia, escolher uma pessoa e contar a história de uma década através dessa pessoa e da sua vida, então era outra maneira. E o próximo livro vai ser totalmente diferente porque eu não quero fazer outra biografia de uma única pessoa. Vou fazer uma biografia coletiva de uma 
geração que vai ser totalmente diferente, com setenta e sete pessoas e sete personagens principais.

Tempo e Argumento: Fale um pouco sobre as suas próximas pesquisas, existe algo em desenvolvimento, algo planejado?

James Green: Sim, tenho dois grandes projetos. Além de reeditar livros que já estão esgotados, vou fazer uma reedição de Além do Carnaval, com um novo capítulo. Também vou reeditar Frescos Trópicos de modo mais caprichado, pois a primeira edição foi feita muito rapidamente: não gostei do resultado, não gostei da capa. Vou fazer ou com essa editora, ou com outra. Vou fazer também uma coletânea de reescritos, chamada Escritos de um Veado Vermelho, que será uma coletânea de artigos que eu já publiquei em vários lugares. Eu pretendo escrever as minhas memórias sobre o Brasil, mas ainda não tenho a menor ideia de como fazer isso, vai ser muito complicado. De novo vou ter que inventar como fazer algo diferente, pois autobiografia não é biografia, é diferente. Além disso, quando escrevi Além do Carnaval eu descobri que a Praça Tiradentes era um lugar de encontros, de sociabilidades no Rio de Janeiro, pelo menos desde 1860, quando eles erigiram a estátua de Dom Pedro I. E eu tenho muita curiosidade de entender essa convivência nesse espaço dentro da cidade do Rio de Janeiro, e por isso vai ser um livro com o título Lazer e Prazer no Rio de Janeiro entre 1860 e 1930, no qual quero analisar como as prostitutas, os gays, os atores e atrizes de teatro, a alta sociedade que circulava nesse espaço assistindo a peças teatrais, os vendedores, etc. conviviam no centro da cidade. E na realidade é para realmente tentar pesquisar mais sobre o século XIX, que ainda é uma incógnita. Eu tenho muitos livros e projetos, não sei se vou conseguir fazer todos. Ideias não faltam, o problema é ter tempo para implementálas. 
Tempo e Argumento: Fale sobre as atividades do Brown's Brazil Initiative, do qual você é diretor.

James Green: Nós tínhamos uma meta de criar o melhor centro de estudos sobre o Brasil fora do Brasil. O Brown's Brazil Initiative é uma tentativa de oferecer uma programação intelectual sobre o Brasil que trabalha com várias temáticas, como a situação atual, a situação especialmente dos afrodescendentes, com pesquisadores afrodescendentes e pessoas que pesquisam os afrodescendentes brasileiros. Tratase também de um lugar de encontro e compartilhamento entre estudantes que estão interessados no Brasil e brasileiros que estão estudando em nossa universidade. Tivemos sorte de ter um pró-reitor que financiou o nosso projeto durante um bom tempo, então tivemos recursos para convidar muitas pessoas. Temos um grande desafio agora para obter de outros modos esse tipo de apoio para o nosso trabalho. É uma coisa muito gostosa. Estamos bem conscientes da importância de sermos um centro de trocas de informações sobre o Brasil, e isso nos ajuda também a ser uma ponte de resistência.

Tempo e Argumento: Existe alguma pesquisa futura relacionada ao Brasil nesse centro?

James Green: Diferente do Brasil - vocês historiadores daqui estudam o Brasil nos departamentos de história -, eu sou o único historiador nesse momento que estuda o Brasil na minha universidade. Há sete latino-americanistas que estudam mais sobre Cuba, México e outros países. Então, eu não tenho uma linha de pesquisa com pessoas da minha universidade, e assim tenho que inventar linhas de pesquisas e colaborações em nível nacional e internacional. Essa conferência que pretendemos organizar sobre a História Social da Homossexualidade no Brasil reflete a minha linha de pesquisa e o meu projeto. Nela, almejamos juntar pessoas daqui e alguns americanos para trocarmos ideias e trabalharmos coletivamente. É outra maneira de trabalhar. Como vocês podem perceber, aqui no Brasil há várias professoras que estão na linha de pesquisa sobre gênero, o que não acontece nos Estados Unidos. Temos pessoas que trabalham sobre o Brasil em vários departamentos, sobre vários 
assuntos, mas um trabalha sobre o meio ambiente, outro trabalha sobre a AIDS, outro sobre o desmatamento da mata atlântica, outro trabalha sobre literatura e democracia, outro sobre Machado de Assis etc., então é uma diversidade de interesses plurais que seria impossível juntar. Porém, pretendemos organizar em abril, se conseguirmos recursos, uma conferência sobre resistência na história, na cultura e na sociedade. Seria uma maneira de juntar parceiros nossos, que já têm laços conosco ao longo dos anos, com pesquisadores americanos para repensar o Brasil no passado, no presente e no futuro. Ainda estamos, independentemente de quem seja o presidente, num momento de resistência aqui. Portanto, queremos pensar esta questão, o que nos ajuda não só em nossas elaborações intelectuais, mas também a pensar em outros laços de colaboração entre norte-americanos e brasileiros.

Universidade do Estado de Santa Catarina - UDESC Programa de Pós-Graduação em História - PPGH Revista Tempo e Argumento Volume 10 - Número 25 - Ano 2018 tempoeargumento@gmail.com 